Most myths are attractive and have their origins in some profound universal truth, so let us discard this one as I am sure it is only the monkey pulling the leg of Homo sapiens. - I am, etc.,

Norwich.

R. C. Howard.

\title{
Vesico-vaginal Fistula
}

SIR,-It occurs to me on reading Mr. I. R. McFadyen's very interesting description of his work on a difficult group of the most difficult condition of vesico-vaginal fistula (December 29, p. 1717) that possibly the "double stop" suture which has proved so successful in hypospadias $^{1}$ and urethral stricture ${ }^{2}$ might be used in closing the vaginal tissues. It has the advantage that it does not strangle the blood supply of the tissues it controls, as does the mattress suture, and is easily removed by cutting the ligature between the two stops without touching the patient. The necessary beads and aluminium stops can be obtained from Messrs. Down Bros., of New Cavendish Street, London.-I am, etc.,

London W.1. REFERENCES

Browne, D., Postgrad. med. J., 1949, 25, 367

2 Johansen, B., Acta chir. scand., 1953, Supp. 176.

\section{Postgraduate Medical Education}

SIR,-Following the conservatively worded report of the Committee inquiring into postgraduate medical education in Great Britain, I am prompted to briefly record my experience as a "Commonwealth doctor" in Great Britain. I wonder how many other British and Commonwealth-educated doctors have had similar experiences. Features about a six-months house physician's appointment in a London hospital with over 300 beds included:

1. No library facilities bar a few meagre shelves of bound journals in the consultant's locked lounge.

2. No clinicopathological or other conferences.

3. No contact between consultant and resident staff outside the weekly ward rounds.

4. Fifteen- to twenty-minute necropsies never attended by clinical consultants, during which no section of tissue was ever taken for histological section.

To label the above type of appointment, which was vital for registration, as a necessary adjunct to medical school is a travesty.

Further experiences as a " trainee" in microbiology provide further food for thought, such as :

1. Training by technicians only.

2. Again no contact with consultants.

3. Few scientific discussions.

4. No access to research programmes.

5. Above all, no criticism.

Until some national standards in postgraduate medicine are set, and the pedestal on which consultant staff stand, protected by the screen of membership or fellowship, is thrust aside, postgraduate medical education in Britain will continue to stagnate.-I am, etc.,

Department of Pathology,

University of North Dakota,

Grand Forks, North Dakota, U.S.A.

\section{P. G. IsAacson.}

\section{Better General Practice}

SIR,-The British Medical Journal of November 17, p. 1311, includes an article "Towards Better General Practice." I am not sure my motives in commenting on this article are entirely admirable. Frankly I am prompted by the many and recurring criticisms of North American medical practice in your esteemed journal. I approach the subject of motivation with typical Anglo-Saxon reticence. Sufficient to say, however, that to most of us the patient is more important than the dollar. Reward for our services in this country is adequate and little time need be wasted on this score. In fact we spend more time telling the secretary who not to bill than in any other aspect of the administration of the practice.

To get back to the article in question. The English general practitioner and his Canadian counterpart are poles apart. An iron curtain exists between us. How, I must ask you, can five doctors practise medicine in your proposed design for practice number 2 ? I count three consulting-rooms, one examination cubicle, and one combined minor surgery and district nurse office. This is inadequate accommodation for two Canadian doctors. Or can it be that most English patients do not require an examination? In my own quarters we have three doctors, three consulting-rooms, each with an examination-room adjoining. Besides this, much of our minor surgery is done in the casualty department of a cottage hospital near by ; our office includes also a small laboratory for urinalysis, haemoglobins, etc., a larger laboratory with a graduate technician for all the other laboratory procedures required. Our $x$-ray work is all done in the hospital by an $x$-ray technician-nurse. Films are checked and reported on by a radiologist.

I am forced to comment also on another attitude which separates the profession in our two countries. All Canadian patients are private patients-the duchess to the dairymaid, the pay and the no-pay, the insured and the uninsured. In fact the patient's status depends on his illness, not his ability to pay twice for a servicefor that is what your "private patients" are doing, is it not?

Finally, please exclude Canada as one of those "most other countries where the evening surgery is unknown." The evening surgery is the rule in general practice in this country. Our offices remain open until the last patient is seen.

Pardon me if I have been rather blunt, but the article in question is not the first, merely the latest, to emerge from the smog into which British general practice has disappeared.-I am, etc.,

$$
\begin{aligned}
& \text { Wakefield, Quebec, } \\
& \text { Canada. }
\end{aligned}
$$

SiR,-I could not agree more with Dr. Brian Hawkes (December 22, p. 1682) when he says, "In the ultimate analysis the overall standard of treatment and care is conditioned not only by professional integrity but by the collective sense of responsibility of the patients themselves." If we are going to wait for this sense to be instilled officially, we are going to have to wait a very long time. Politicians would be apprehensive about the reception of any official homilies on the subject, and would not risk losing the votes of millions of patients for those of a few thousand doctors.

There is no need, however, for a doctor's wife to be a dragon. If she has this reputation it is doubtless earned, and reflects a husband who is a poor organizer and has not the courage to educate his patients to think calmly and be considerate. With the undergraduate training of doctors in the hands of consultants, the majority of students qualify without realizing their 